\title{
Corrosion testing of experimental steels for oilfield pipelines
}

\author{
Alexey Alkhimenko* \\ Peter the Great St. Petersburg Polytechnic University, 195251 St. Petersburg, Russia
}

\begin{abstract}
Emergency equipment failures at oilfield pipelines are often associated with corrosion damage of the pipe material. Optimization of the chemical composition of the used steel can play a significant role in increasing the corrosion resistance under the condition of ensuring the metallurgical quality of pipes. This article presents a comparative assessment of the corrosion resistance of the used Fe-Cr-Cu-Mn-V steel and experimental compositions, basing on the results of electrochemical studies and tests for general corrosion.
\end{abstract}

\section{Introduction}

Oil is transported at the oilfields by a system of pipelines. Oil is not a corrosive medium, but the presence of salts, chlorine ions, et al in the fluid significantly increases its corrosion activity. So, for example, hydrogen sulfide, dissolved in oil, is the main cause of corrosion damage to steels of various classes, leading to accidents with economic and environmental losses [1,2]. In this regard, the investigation of new and used steels in the oil industry in order to increase the reliability and durability of actively used oil pipelines is undoubtedly an urgent task of practical interest.

For oilfield pipelines, one of the main hazards is general and local corrosion. The main feature of steel behavior in corrosive environments is the possibility of evolution of corrosion processes according to the classical electrochemical mechanism. The typical kinds of corrosion are pit, groove or rill, which are located strictly along the lower generating line of pipes.

In case when pipe products meet the requirements of the existing regulatory documents, the increased accident rate may indicate insufficient corrosion resistance of steel. Under these circumstances, materials science approach is the most rational. It consists in increasing the corrosion resistance by optimizing the alloying composition and improving the metallurgical quality of metal.

The technological process of metallurgical production of rolled sheet is a multifactorial system, in particular, consisting of smelting, rolling and thermomechanical processing. Each stage of this system contributes to ensuring the metallurgical quality of the individual sheet product, its structure and properties, the content of corrosive non-metallic inclusions in steel, as well as sulfur and phosphorus impurities, which have a direct impact on corrosion resistance $[3,4]$.

The corrosion resistance of steel also depends on its chemical composition. The main alloying elements which have an effect on the corrosion rate, or, more precisely, affect the structural and phase composition of steel, in low-alloy structural steels are carbon, chromium, copper and manganese [5,6].

The positive impact of chromium is associated with the formation of protective films which reduce the rate of corrosion. As for copper, it is believed that its content in steel in the range of $0.2-0.3 \%$ not only increases the corrosion resistance in the atmosphere of the environment, but also somewhat slows down its dissolution in hydrochloric and sulfuric acids, and also increases the resistance to hydrogen sulfide cracking. Due to the combination of alloying components, a positive effect is achieved, which consists in increasing the degree of equilibrium of the structure.

One of the current trends in creation of new steels for oil-field pipelines is the development and use of economically alloyed steels.

This article provides an assessment of the corrosion rate when testing steels of experimental compositions for oilfield pipelines.

\section{Materials and methods}

This article presents the results of assessment the corrosion rate for 4 variants of experimental compositions of steel (steel 1 - 4), and for 1 used steel (Fe-Cr-Cu-Mn-V - Used steel) for comparing its corrosion resistance (Table 1).

Table 1. Chemical composition of the studied steels.

\begin{tabular}{|c|c|c|c|c|c|}
\hline Mass \% & $\mathbf{C}$ & $\mathbf{C r}$ & $\mathbf{C u}$ & $\mathbf{M n}$ & $\mathbf{V}$ \\
\hline Steel 1 & 0.23 & 4.49 & 0.27 & 1.09 & 0.10 \\
\hline Steel 2 & 0.06 & 0.27 & 0.96 & 1.16 & 0.04 \\
\hline Steel 3 & 0.24 & 0.07 & 0.01 & 1.22 & - \\
\hline
\end{tabular}




\begin{tabular}{|c|c|c|c|c|c|}
\hline Mass \% & $\mathbf{C}$ & $\mathbf{C r}$ & $\mathbf{C u}$ & $\mathbf{M n}$ & $\mathbf{V}$ \\
\hline Steel 4 & 0.17 & 0.32 & 0.22 & 1.00 & - \\
\hline $\begin{array}{c}\text { Used } \\
\text { steel }\end{array}$ & 0.13 & 0.57 & 0.21 & 0.55 & 0.07 \\
\hline
\end{tabular}

Steel 1 has a high chromium content and, respectively, the higher strength compared with the other studied compositions. Experimental steel 2 has a lower chromium content and a high copper content (4 times higher than the copper level for the Fe-Cr-Cu-Mn-V used steel). In the steel 3chromium and copper are practically absent, while in the steel 4 their value are at the level of $0.2-0.3$ mass $\%$.

The corrosion susceptibility was determined from electrochemical studies and direct corrosion tests when samples were exposed to a corrosive environment. When conducting electrochemical studies, a neutral aerated 5\% aqueous solution of sodium chloride and a deaerated solution acidified at $\mathrm{pH}$ 2.6-2.8 were used as corrosive solutions. Direct tests for general corrosion were carried out using a neutral aqueous solution of $5 \% \mathrm{NaCl}$, in which corrosion proceeds at oxygen depolarization.

\section{Test results and corrosion rate assessment}

The rate of corrosion damage evolution is related to the resistance of steel to general corrosion. From the point of view of classical concepts of electrochemical corrosion, steel with the most positive corrosion potential (steel 1 and steel 2) will be the most corrosion-resistant, and the experimental composition steel 3 will be the least resistant in all cases. The test results confirmed that the steel of experimental compositions (besides steel 3), must corrode at a slower rate than $\mathrm{Fe}-\mathrm{Cr}-\mathrm{Cu}-\mathrm{Mn}-\mathrm{V}$ used steel. Direct corrosion tests were carried out with exposition of 240 hours. The results of the corrosion tests are presented in Table 2.

Table 2. The results of the corrosion tests.

\begin{tabular}{|c|c|c|c|c|c|c|}
\hline \multirow{3}{*}{ - } & \multicolumn{4}{|c|}{ Electrochemical Studies } & \multirow{2}{*}{\multicolumn{2}{|c|}{$\begin{array}{c}\text { Direct Tests } \\
\begin{array}{c}5 \% \mathrm{NaCl} \\
\text { (neutral) }\end{array}\end{array}$}} \\
\hline & \multicolumn{2}{|c|}{$\begin{array}{c}5 \% \mathrm{NaCl} \\
\text { (acidified) }\end{array}$} & \multicolumn{2}{|c|}{$\begin{array}{c}5 \% \mathrm{NaCl} \\
\text { (neutral) }\end{array}$} & & \\
\hline & 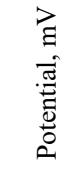 & 音 & 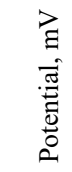 & Uี & 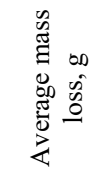 & है \\
\hline $\begin{array}{c}\text { Steel } \\
1\end{array}$ & -571 & 0.03 & -514 & $\mathbf{0 . 0 3}$ & 0.017 & 0.04 \\
\hline $\begin{array}{c}\text { Steel } \\
2\end{array}$ & -545 & 0.07 & -578 & 0.05 & 0.039 & 0.05 \\
\hline $\begin{array}{c}\text { Steel } \\
\mathbf{3}\end{array}$ & -626 & 0.40 & -668 & 0.11 & 0.042 & 0.06 \\
\hline
\end{tabular}

\begin{tabular}{|c|c|c|c|c|c|c|}
\hline \multirow[b]{3}{*}{-} & \multicolumn{4}{|c|}{ Electrochemical Studies } & \multirow{2}{*}{\multicolumn{2}{|c|}{$\begin{array}{c}\text { Direct Tests } \\
5 \% \mathrm{NaCl} \\
\text { (neutral) }\end{array}$}} \\
\hline & \multicolumn{2}{|c|}{$\begin{array}{c}5 \% \mathrm{NaCl} \\
\text { (acidified) }\end{array}$} & \multicolumn{2}{|c|}{$\begin{array}{l}5 \% \mathrm{NaCl} \\
\text { (neutral) }\end{array}$} & & \\
\hline & 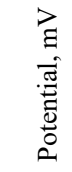 & 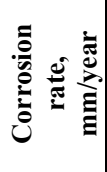 & 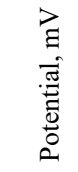 & 音 & 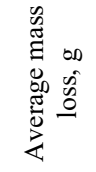 & 氡 \\
\hline $\begin{array}{c}\text { Steel } \\
4\end{array}$ & -577 & 0.18 & -571 & 0.04 & 0.042 & 0.06 \\
\hline $\begin{array}{l}\text { Used } \\
\text { steel }\end{array}$ & -604 & 0.32 & -590 & 0.07 & 0.046 & 0.07 \\
\hline
\end{tabular}

The comparative corrosion tests showed that almost in all cases, the steels of experimental compositions have more advantages compared to the Fe-Cr-Cu-Mn-V used steel, except for the $\mathrm{Cr}-\mathrm{Cu}$-depleted steel 3 experimental composition.

It was found that steel 1 has the most corrosionresistant composition in a neutral medium of $5 \% \mathrm{NaCl}$, as well as in acidified medium. This steel has the highest corrosion potential and a relatively high chromium content. A higher copper content (in steel 2 in comparison with steel 4) with a practically identical chromium content did not greatly affect their level of corrosion resistance.

Tests for general corrosion in a neutral medium of $5 \% \mathrm{NaCl}$ with free access of air showed practically the same average corrosion rate for all investigated steels at a level of $0.05 \pm 0.01 \mathrm{~mm} /$ year.

\section{Conclusions}

One of the main causes of accidents at oilfield pipelines is corrosion of the inner pipe surface, which is in contact with the watered medium containing aggressive components and impurities. According to the results of electrochemical studies and direct corrosion tests, the experimental alloying compositions steel 1 and steel 2 turned out to be the most corrosion-resistant, but steel 2 is less alloyed and, accordingly, it is economically more attractive for further study.

\section{References}

1. I.G. Rodionova, O.N. Baklanova, et al. Metallurgist, 49 (5-6), 173-182 (2005)

2. I.S. Sivokon, N.N. Andreev, Int. J. Corros. Scale Inhib. 3 (2), 101-104 (2014)

3. J.I. Barraza-Fierro, B. Campillo-Illanes, et al. Metall. Mater. Trans. A, 45 (9), 3981 - 3994 (2014)

4. K.A. Udod, I.G. Rodionova, et al. Metallurgist, 59 (11-12), 1096-1100 (2016)

5. Y. Hyun, H. Kim, Korean J. of Metals and Materials, 54, 68-78 (2016)

6. H.S. Klapper, J. Stevens, CORROSION/2015 (NACE-ICCS), paper no. 51315 (2015) 